\title{
Chapter 1 \\ Relevance of Western Medicine and TCM in the Chinese and European Markets: An Overview
}

\author{
Attilio Mucelli
}

\section{INTRODUCTION}

Traditional Chinese Medicine (TCM) was developed more than 2,500 years ago as a system for studying human physiology and pathology, as well as for preventing, diagnosing, and treating illnesses. The most common TCM practices include herbal and nutritional therapy, restorative physical exercises (qigong), meditation, acupuncture (stimulating specific points of the body using various techniques), remedial massage (tuina), moxibustion (applying heat to acupuncture points by burning herbs above the skin's surface) and tai chi (dance-like body movements combined with coordinated breathing and mental focus). ${ }^{1}$

Over the period 2003-2011, it was estimated that the TCM industry sales had a 24\% Compounded Average Growth Rate (CAGR), with respect to the $21 \%$ for Western Medicine (WM), indicating that it is not only one of the fastest emerging activities within the Chinese territory but 
also an increasingly recognized practice abroad. In value terms, TCM reached USD 14.135 million by $2014 .^{2}$

From 2007 to 2014, the fastest growing suppliers of raw materials for TCM were Thailand (+59.7\% per year) and Germany (+35.7\% per year).

According to the China Chamber of Commerce for Import \& Export of Medicines \& Health Products (CCCMHPIE), the exports of TCM products from China had increased by $25.54 \%$ (totaling USD 3.14 billion) in 2013, thanks to the rising international demand for Chinese herbal medicine. ${ }^{3}$ The CCCMHPIE reported that, in 2012, China's top 10 export markets included only Germany and France among the EU countries, ${ }^{4}$ while the leading destinations of TCM exports in 2014 were Japan, Indonesia, the Philippines, Malaysia, and Thailand, which together comprised $44.8 \%$ of TCM export volume.

According to China Daily, the global promotion of TCM has been boosted by the establishment of an official relationship between the World Federation of Chinese Medicine Societies (WFCMS) and the World Health Organization (WHO), in order to provide technical support to the WHO as well as achieve cooperation with other nongovernmental institutions. ${ }^{1}$

While TCM has been expanding abroad, WM in China has become increasingly popular. An analysis of the revenue composition in TCM hospitals in China showed that, from 1999 to 2008, the percentage revenue coming from WM increased from $59.6 \%$ to $66.1 \%$, whereas that from TCM declined from $18 \%$ to $13.7 \% .^{5}$ It is obvious that WM represents a key financial source for the survival of TCM hospitals, which mainly generate revenues by providing WM services. The main reasons for this trend is related to the significant decline in government subsidies toward healthcare facilities, as well as to the fall in the demand for TCM services: $94.8 \%$ of rural residents and $84.9 \%$ of healthcare providers admitted to seeking WM care as the first choice, compared to $5.2 \%$ and $15.1 \%$, respectively, of those opting for TCM therapies first. ${ }^{5}$

\section{THE ROLE OF TCM IN THE CHINESE CONTEXT}

The regulation on TCM is embedded into the Chinese constitution. Regulation of TCM by the People's Republic of China in 1982 affirms that the State protects, supports, and promotes the development of TCM, 
as well as its integration with WM (both types of medicine have equal importance, should complement each other, and improve through mutual learning and knowledge exchange). There is a TCM Department at the Ministry of Public Health, ${ }^{6}$ and the responsibility of formulating all of the related regulations, policies, and guidelines are entrusted to the State Administration of TCM, which also has the task to build its standardized management and development. ${ }^{7}$ TCM is fully covered under the government and private insurance schemes. Patients have the right to freely choose which type of medicine to resort to (either traditional or conventional), and TCM practitioners are able to practice in either public or private hospitals and clinics. ${ }^{8}$

In 2012, TCM accounted for $31.24 \%$ of the entire domestic medicine market (with expenses above USD 79.5 billion), according to the National Bureau of Statistics in China. ${ }^{9}$

The China Academy of the Chinese Medical Sciences assessed that, by 2013, the total output value of TCM had already reached one-third of the domestic medicine industry (estimated at USD 91.4 billion). ${ }^{10}$ The yearly revenue growth of $18.1 \%$ (from 2008) led to a total of USD 29.6 billion during the same year, thanks to the increasing demand for these services by the patients. The top four industry competitors accounted for almost $3.1 \%$ of the entire industry revenue that year, as estimated by IBIS World (whereas the top eight participants held a combined share of less than 5\%). In 2013, the number of TCM hospitals was estimated to be around 2,930, each with an average of 196 beds. ${ }^{11}$ In terms of higher education institutions, by 2013, 45 schools were dedicated to TCM and 93 were specialized in WM. ${ }^{7}$ In 2014, the visits to TCM hospitals accounted for $17.9 \%$ of the total hospital visits across the country (530 million visits) and the overall value of the TCM industry increased to USD 110.8 billion. ${ }^{12}$

The revenue of the TCM hospital industry in 2016 rose to USD 53.7 billion, which represented an $11.8 \%$ growth from 2015. On the whole, there has been an annualized revenue expansion of $16.3 \%$ from 2011 till 2016. In terms of profitability, estimates went from $0.9 \%$ in 2007 up to $4.6 \%$ in 2016.

At present, there are nearly 440,700 Chinese healthcare institutions at all levels (from general hospitals, clinics, and health stations in both urban and rural areas to TCM hospitals), offering TCM services: approximately 
$90 \%$ of the general hospitals include a TCM department, for inpatients and outpatients alike, ${ }^{8}$ while the TCM institutions account for $4.3 \%$ of the total. $^{7}$ The total number of TCM hospitals in China have increased by 500 in the past five years $(+15.5 \%)$ : there are about 3,059 TCM hospitals to date, with 252 beds on average, employing around 831,463 people. ${ }^{11}$ The TCM outpatient departments increased as well (by 531) and so did the TCM clinics (by 5,890). ${ }^{12}$

\section{TCM STILL LAGS BEHIND IN EUROPE}

In 2010, the WFCMS estimated that there were about 120,000 TCM practitioners and acupuncturists in Europe at the time. By that year, acupuncture as a distinct therapeutic system was recognized by law in $12 \mathrm{EU}$ Member States, including Austria, Belgium, Bulgaria, Czech Republic, Denmark, Germany, Greece, Hungary, Latvia, Portugal, Slovenia, and Spain. $^{7}$

In 2012, only $10 \%$ of China's total TCM export volume went to the EU (e.g., the exports to the UK dropped by 70\%). ${ }^{13}$ Nevertheless, over the past four years, a significant number of TCM products entered the EU market, corresponding to annual export sales of traditional Chinese herbal medicinal products to the EU of around USD 12 million (CCCMHPIE data). ${ }^{14}$ Germany represents the main European TCM market, from which an expansion toward other EU countries can be easily achieved. In general, the EU is a high-potential market for herbal medicine trade: it is estimated to have a $47 \%$ share in the global herbal market (USD 26 billion), with more than 1,270 types of herbal medicines in circulation, and over $60 \%$ Europeans using TCM. ${ }^{15}$

The main trade barrier for the development of TCM in Europe is related to the EU Directive 2004/24/EC, also known as Traditional Herbal Medicinal Products Directive (THMPD), which provides the legal basis for TCM and other types of herbal medicines, in terms of entry into the EU market. ${ }^{16}$ Its objective is the establishment of a unified regulatory regime for the medicinal products market across all the member nations (each Member State had then to apply their own rules/procedures to regulate TCM accordingly). THMPD planned to introduce a simplified registration procedure of such products, which would have been subject to the 
EU quality and safety guarantees (this was particularly important as some TCM products had a very poor reputation of quality in other markets: they were either mixed with WM; contained heavy metal, rare animals, or plants; or lacked specifications regarding shelf life). ${ }^{17}$

The Directive stipulated that only those TCM products that had obtained the authorization could be sold within the EU (with a safety proof of utilization of 30 years, 15 of which within the EU). ${ }^{18}$ After a transitional period of seven years (till April 2011), the products that were not registered yet could not be imported into the EU market: the products had to meet the definition of "traditional medical product" and the representative Chinese TCM producers and exporters should have applied for a marketing authorization well in advance, in order to benefit from the transitional period and be able to sell their products in the EU market as medicines (those products that were already marketed in the EU when the Directive entered into force in 2004 had an advantage, but without a marketing authorization, they could not be placed on the EU market as medicines).

However, the challenge of isolating the specific ingredients for the complex Chinese medicines on one hand (unlike WM), and the limited share of TCM in Europe on the other, made it difficult for the Chinese companies to go through the registration process. ${ }^{15}$

Moreover, the huge costs of obtaining approval in the EU for each specific TCM product was estimated to be around USD 650,000-800,000 (USD 160,000 to file and USD 650,000 to upgrade management and production equipment in order to meet EU's standards for Good Manufacturing Practice (GMP). ${ }^{13}$ As a result, none of the leading TCM producers had carried out any registration procedures by the 2011 deadline, despite the fact that 350 Chinese herbal substances were licensed during the transitional period. Those products that could not be classified as "drugs", and were therefore excluded from the most lucrative markets, were often marketed in the EU under other product designations (once they met the related EU requirements), such as "food", "nutrition products" or "cosmetics". ${ }^{19}$

In June 2011, TCM exports dropped, as reported by the CCCMHPIE, and $99 \%$ of the 10,000 kinds of TCM that were sold as medicines in the EU before that period were prevented from accessing the EU market. 
While in 2008, data on the trade of Chinese herbal medicines and extract to the EU suggest an increase in exports (the Netherlands market increased most rapidly, followed by Germany in terms of value), from 2011 to 2012, the exports of Chinese herbal medicines (CPD) declined $(-14.64 \%$ in the Netherlands, $-69.81 \%$ in the UK, but $+32.67 \%$ in Germany, which was the first country to make registration of TM mandatory $\left.{ }^{15}\right)$ in value and volume $(-13.5 \%)$.

In addition, the uneven registration pattern across the Member States shows the fragmentation (different rules applied in each territory) of the EU market as well as the incapability of the EU regime to reach market integration. In 2013, two years after the transition period, a total of only 110 applications to the registration scheme were observed in 25 European countries: some of them had more than 20 applications while in the majority, there were few to nil applications. ${ }^{17}$

\section{REFERENCES}

1. Burke, A., Kaptchuk, T., Lao, L., Weber, W. \& Killen, J. (2013). Traditional Chinese Medicine: An Introduction (U.S. Department of Health and Human Services, Washington, DC), pp. 1-4.

2. IndexBox Marketing (2015). China: Traditional Chinese Medicine Market Report. Analysis and Forecast to 2020 (IndexBox Marketing, South Lanarkshire, Scotland).

3. Taylor, L. (2014). "China's pharma export trade growth slows," PharmaTimes. Available at: http://www.pharmatimes.com/news/chinas_pharma_export_trade_ growth_slows_100155. Accessed 31 August 2017.

4. Wu, Q., Yang, D., Ge, J., Li, Z., Su, Z. \& Mucelli, A. (2017). Introduction and Analysis of Chinese Health Care Situation and Cooperation Opportunities between China and Europe, CHETCH Project Material.

5. Shen, J. J., Wang, Y., Lin, F., Lu, J., Moseley, C. B., Sun, M. \& Hao, M. (2011). "Trends of increase in Western medical services in traditional medicine hospitals in China," BMC Health Services Research, 11: 212.

6. Robinson, N., Lorenc, A., Ding, W., Jia, J., Bovey, M. \& Wang, X. (2012). "Exploring practice characteristics and research priorities of practitioners of traditional acupuncture in China and the EU - A survey," Journal of Ethnopharmacology, 140(3): 604-613.

7. Yang, L., Cavicchi, A. \& Croci Angelini, E. (2015). Report of European firms in China and Chinese firms investing in Europe, CHETCH Project Material. 
8. World Health Organization (2013). WHO Traditional Medicine Strategy 2014-2023 (World Health Organization, Hong Kong), p. 37.

9. Thibaud, A. (2014). Traditional Chinese Medicine: A Profitable Worldwide Trend (LCB Editors).

10. SSRI China (2014). "TCMs expected to play a bigger role in China's medical reform," China Medical News.

11. Smith, G. (2017). Traditional Chinese Medicine Hospitals in China: Industry Research Report. IBIS World.

12. SSRI China (2016). "Traditional Chinese Medicine (TCM) on the rise," China Medical News.

13. Cai, C. (2014). "A hard pill to swallow," China Pictorial. Available at: http:// www.chinapictorial.com.cn/en/industry/txt/2013-11/04/content_575834. htm.

14. Wang, M. \& Franz, G. (2015). "The role of the European pharmacopoeia $(\mathrm{Ph}$ Eur) in quality control of traditional Chinese herbal medicine in European Member States," World Journal of Traditional Chinese Medicine, 1(1): 5-15.

15. Yun, L. (2013). "Testing times ahead for TCM," China Daily Europe.

16. Dong, Z. Present Situation and Future of TCM in Europe (Pan European Federation of TCM Association's material).

17. Snyder, F., Lu, Y. \& Yazdani G. (2013). "Traditional Chinese Medicine and European Union Law: Cultural logics, product identities, market competition, legal rechanneling, and the need for global legal and medical pluralism," Peking University Law Journal, 15(2). Shenzhen, research paper 15-2, pp. 2-57.

18. Yang, J. \& Devapriyo, D. (2011). "Traditional Chinese medicine gains ground in Denmark," English News. Available at: http://news.xinhuanet.com/ english2010/health/2011-05/01/c_13854000.htm.

19. HSBC (2015). "Returning to tradition: Chinese medicine regaining traction in domestic healthcare market," Week in China. 